\title{
Bronchial lavage in the treatment of obstructive lung disease
}

\author{
H. T. THOMPSON, W. J. PRYOR, AND JACQUELINE HILL \\ From the Thoracic Department, the Princess Margaret Hospital, Christchurch, New Zealand
}

In 1964 we first reported the use of bronchial lavage in obstructive lung disease, noting that in cases of intractable asthma especially the production of bronchial casts was associated with a dramatic improvement in the patient's respiratory capacity. Further experience has confirmed the usefulness of this procedure, and we wish to report on the management of 92 patients who have been followed up for a period of from one to four years.

The primary indication for this treatment remains the case of intractable asthma, although a number of patients with bronchitis and emphysema have been helped considerably.

\section{TECHNIQUE}

SURGICAL The patient is bronchoscoped under general anaesthesia. Using a $50 \mathrm{ml}$. syringe and a metal bronchial catheter with a curved end over which a polythene sleeve has been fitted, physiological saline is injected into each lobar and segmental bronchus within the range of bronchoscopic vision. This procedure washes out mucous casts, which are then aspirated through the same catheter. It has been suggested that a mucolytic agent or detergent could be used in the lavage fluid. Usually 800 to $1,500 \mathrm{ml}$. of saline is required, and as only 25 to $30 \%$ of this is recovered by suction serious electrolyte disturbance or even haemolysis might be produced if such substances were used. In addition the bronchial mucosa is very sensitive, and even lavage with saline may produce an exacerbation of bronchitis, which might be greatly intensified if less physiological solutions were used.

ANAESTHETIC This has been modified very considerably in the light of experience. Although we continue to use ether, as we feel it is a most effective bronchodilator, the inhalational induction we recommended formerly has been abandoned because of its tediousness in patients with such poor ventilatory capacity. Moreover, in some cases it proved difficult to attain sufficient depth of anaesthesia to perform the lavage without producing paroxysmal bronchospasm. Our present technique is to induce anaesthesia with a sleep dose of $2.5 \%$ thiopentone, followed by 40 to 50 mg. suxamethonium. The patient is inflated with oxygen, and $5 \mathrm{ml}$. of $2 \%$ lignocaine is instilled into the trachea. A cuffed tube is inserted and the patient is inflated with an oxygen-ether mixture in a closed circuit. Suxamethonium is used in order to introduce sufficient ether into the patient in a reasonably short time. The concentration of ether is gradually built up until the pupils are half dilated. Care must be taken not to build up the ether concentration too rapidly or cardiovascular collapse may occur. At this stage the ether is replaced by $1 \%$ halothane five minutes before bronchoscopy is performed. This allows time for the inhaled mixture to become nonexplosive (Vickers, 1965). The halothane-oxygen mixture is continued via the side tube of the bronchoscope, and it may be necessary in the poor-risk patient to remove the bronchoscope and reinsert the cuffed tube to re-oxygenate the patient several times during the lavage.

\section{MANAGEMENT}

Bronchial lavage is merely an incident in the management of patients with obstructive lung disease. Breathing exercises, antispasmodics, steroids, and, where necessary, antibiotics are all tried before lavage is considered. Although we may hesitate to carry out this procedure in very ill patients with gross emphysema, no patient in status asthmaticus is considered too ill, and some of our most dramatic results have occurred in patients who were virtually moribund.

At the conclusion of the operation an intravenous infusion of $500 \mathrm{ml}$. of $5 \%$ glucose containing $1 \mathrm{~g}$. aminophylline, $100 \mathrm{mg}$. hydrocortisone, and $1 \mathrm{ml}$. of 1 in 1,000 adrenaline is given over the next six hours to ensure prolonged bronchodilatation at a period when the patient is coughing vigorously. A flare-up of bronchitis is common post-operatively, and this is treated by intensive physiotherapy and antibiotics. The patient is usually discharged five to seven days after operation and followed up at the out-patient clinic. The first visit is usually after one month, and if the patient's condition is stable visits are then spaced out at longer intervals until after two years the patient is seen annually before being discharged 
after a total of four years' follow-up. Respiratory function tests are carried out at each visit as an aid to the clinical assessment of the patient's progress. The patients are actively encouraged to continue with their breathing exercises, and some seem to require almost permanent supervision by thoracic physiotherapists. Where possible, steroid dosage is tailed off altogether or at least cut down. Many patients, however, require a maintenance dose of 5 to $7.5 \mathrm{mg}$. prednisone per day.

\section{RESULTS}

Between December 1961 and December 1964, 177 lavages were carried out on 92 patients, of whom 50 were males and 42 females, with an age range of from 9 to 76 years. The follow-up period has been from one to four years. The patients have been divided into three main groups, according to the number of lavages they received.

GROUP I Sixty-one patients had one lavage up to December 1964. Twenty-one were greatly improved and have remained so to date. It has been possible to cut out steroids altogether in seven patients in this group, and in three others the steroid dosage was reduced. Sixteen were either significantly improved both clinically and according to their respiratory function tests, or were greatly improved but suffered some degree of relapse. Twenty-four patients were only temporarily improved or showed no improvement after one lavage. One patient died suddenly with airways obstruction unrelieved five days after the lavage. Five other patients in this group have died subsequently, one to two years after bronchial lavage.

GROUP II Twenty-one patients had two or three lavages each, up to December 1964. Nine, each of whom had two lavages, obtained excellent results after the second and have remained well to date. Six patients obtained satisfactory and lasting results. Five obtained only temporary or no improvement. Three of these patients have died, one of respiratory failure following pneumonia about a year after the last lavage; another died 24 hours after a third lavage following an injection of adrenaline. The third patient died suddenly three years after an apparently satisfactory result.

GROUP III Ten patients had 71 lavages, ranging from four to 23, during 1961 to 1964 (and a further 35 lavages in 1965). These patients all produced large numbers of casts and showed clinical improvement which was confirmed by pulmonary function tests. However the improvement, though dramatic, was short-lived, and three of these patients became lavage-dependent. Six patients in this group have died of respiratory failure; four are much improved.

\section{MORBIDITY}

Three patients developed surgical emphysema following lavage. This did not require special treatment and was soon absorbed. One of these was the victim of an anaesthetic explosion, in the early days when we were using an ether-oxygen mixture during bronchoscopy. Two patients required intermittent positive pressure respiration to tide them over the first 24 to 48 hours postlavage.

\section{MORTALITY}

There have been no deaths in this series attributable to the lavage itself. Two patients died unexpectedly in the immediate post-lavage period, one of unrelieved bronchial obstruction in spite of producing many casts ; the other died after an injection of adrenaline. Thirteen other patients in this series have died, five of them suddenly and unexpectedly during asthmatic attacks. Eight have died of respiratory failure.

\section{DISCUSSION}

Obstructive lung disease may be considered as a spectrum with asthma at one end and emphysema at the other. In the centre, overshadowing both these conditions, is chronic bronchitis. In assessing our results we have not only divided our patients according to the number of lavages and the results obtained, but also according to their place in the spectrum (Table I).

It is not surprising to see that most of our good results have been obtained in asthmatics whose condition is at least potentially reversible. However, a significant number of good results have been obtained in patients at the other end of the spectrum, indicating that it is not always possible to rule out a reversible element in some patients with bronchitis and emphysema. It is this group of patients that we find most difficult to assess pre-operatively, as failure to respond to steroids or antispasmodics is not necessarily at this stage an indication of irreversibility. The patients may respond to these drugs after a successful lavage when they have shown no response before. 
T A B L E I

SPECTRUM OF OBSTRUCTIVE LUNG DISEASE IN 92 PATIENTS UNDERGOING BRONCHIAL LAVAGE

\begin{tabular}{c|c|c|c|c}
\hline $\begin{array}{c}\text { Results of } \\
\text { Lavage }\end{array}$ & Asthma & $\begin{array}{c}\text { Asthma } \\
\text { and } \\
\text { Bronchitis }\end{array}$ & $\begin{array}{c}\text { Bronchitis } \\
\text { and } \\
\text { Emphysema } \\
\pm \text { Asthma }\end{array}$ & Total \\
\hline $\begin{array}{c}\text { Group I : } \\
\text { Good .. }\end{array}$ & 2 & 13 & 6 & 21 \\
Fair .. & - & 3 & 13 & 16 \\
Poor .. & 1 & 5 & 18 & 24 \\
Group II: & & 5 & 3 & 9 \\
Good . & 1 & 1 & 5 & 6 \\
Fair .. & - & 1 & 5 & 6 \\
Poor .. & - & 1 & 9 & 10 \\
Group III & - & & &
\end{tabular}

T A B L E II

QUANTITY OF CASTS OBTAINED IN THE THREE GROUPS COMPARED WITH THE CLINICAL RESULTS

\begin{tabular}{|c|c|c|c|c|c|c|c|c|}
\hline \multirow{3}{*}{\multicolumn{2}{|c|}{$\begin{array}{l}\text { Quantity } \\
\text { of Casts } \\
\text { (ml.) }\end{array}$}} & \multicolumn{7}{|c|}{ Result of Lavage } \\
\hline & & \multicolumn{3}{|c|}{ Group I } & \multicolumn{3}{|c|}{ Group II } & \multirow{2}{*}{$\begin{array}{l}\text { Group } \\
\text { III }\end{array}$} \\
\hline & & Good & Fair & Poor & Good & Fair & Poor & \\
\hline $\begin{array}{l}\text { Nil } \\
10-30 \\
30-50 \\
\text { Over } 50\end{array}$ & $\begin{array}{l}. \\
\therefore \\
\therefore\end{array}$ & $\begin{array}{r}4 \\
10 \\
4 \\
3\end{array}$ & $\begin{array}{l}6 \\
6 \\
1 \\
3\end{array}$ & $\begin{array}{r}13 \\
8 \\
3\end{array}$ & $\begin{array}{l}\overline{1} \\
4 \\
4\end{array}$ & $\begin{array}{l}2 \\
2 \\
1 \\
1\end{array}$ & $\begin{array}{r}2 \\
2 \\
2 \\
-\end{array}$ & $\frac{-}{1}$ \\
\hline \multicolumn{2}{|c|}{ Total .. } & 21 & 16 & 24 & 9 & 6 & 6 & 10 \\
\hline
\end{tabular}

At operation a rough estimate of the amount of casts and mucus obtained is made, and from Table II it can be seen that, generally speaking, patients who are significantly improved tend to produce most casts and those with poor results the least. However, there have been a few exceptions where patients who failed to produce any casts obtained significant and prolonged relief, while some of those whose cast production was spectacular obtained only temporary benefit.

Some patients who are only slightly improved by one lavage may obtain prolonged relief after a second or third (16 patients out of 21 in group II). We are guarded about the prognosis of any patient who has not reached a steady state after three lavages, no matter how dramatic the temporary improvement may have been. Although we undoubtedly prolonged the useful lives of the 10 patients in group III, six of them have died in spite of repeated lavages.

\section{SUMMARY}

The results of bronchial lavage in 92 patients with obstructive lung disease are presented. Thirty patients were greatly improved after one or two lavages and have remained so for a period of up to four years. A further 27 patients have remained significantly improved, but 35 were not improved or showed only temporary improvement. In this group, 15 patients have died subsequently.

Status asthmaticus remains the primary indication for bronchial lavage, and some of our most dramatic and lasting results have been obtained in patients who were moribund.

\section{REFERENCES}

Thompson, H. T., and Pryor, W. J. (1964). Bronchial lavage in the treatment of obstructive lung disease. Lancet, 2, 8.

Vickers, M. D. (1965). The duration of the explosive risk after induction with ether or cyclopropane. Anaesthesia, 20, 86 